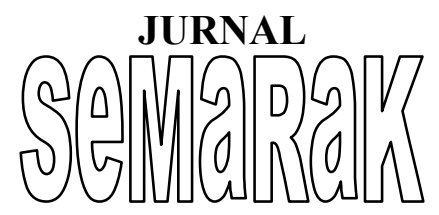

P-ISSN 2615-6849 E-ISSN 2622-3686

Semarak,Vol. 1, No.3,Oktober 2018, Hal (39-48)

@Prodi Manajemen Fakultas Ekonomi Universitas Pamulang

\title{
PENGARUH PELATIHAN DAN KOMUNIKASI TERHADAP KINERJA KARYAWAN PADA KLINIK TUMBUH KEMBANG YAMET PAMULANG
}

\author{
Oleh : \\ Fahmi Susanti \\ Fakultas Ekonomi Program Studi Manajemen \\ E-mail: fahmi.susanti.arif@gmail.com
}

\begin{abstract}
ABSTRAK
Tujuan yang diinginkan agar menemukan "pengaruh Pelatihan serta Komunikasi terhadap kinerja karyawan" pada klinik Yamet, dengan cara" parsial" atau "simultan." Dalam penyusunan penelitian memakai methode "deskriptip kuantitatif." Dengan responden sebanyak 50 serta sampel sebanyak 50 karyawan, cara pengambilan sampel, secara sampel yang jenuh setiap respondenn mendapat kesamaan dalam peluang. Dianalisis dengan metode "regresi linier ganda." Hasil uji hipostesis pelatihan serta komunikasi, secara parsial nilai thitung masing-masing sebesar 6,528 dan 9,590 dimana semua nilai $t_{\text {hitung }}>t_{\text {tabel. }}$. tabel 1,677 Untuk pengaruh simultan diperoleh $F_{\text {hitung }}>F_{\text {tabel }}$ yaitu $13,08>3,20 . \alpha=0,05$ taraf signifikan. Kesimpulan yang diperoleh dengan parsial maupun simultan pelatihan serta komunikasi mempunyai pengaruh yang sangat berarti dengan "kinerja karyawan". Dengan persamaan regresi linier $\hat{Y}=-0,026+0,001 \mathrm{X}_{1}+$ $0,048 \mathrm{X}_{2}$ artinya pelatihan dan komunikasi memiiki kemampuan untuk mempengaruhi kinerjanya karyawan. Nilai koefisien determinasi 0,982 atau sebesar 98,2\% menjelaskan bahwa pelatihan dan komunikasi berkemampuan untuk mempengaruhi kinerjanya karyawan sebesar 98,2 \% serta kemampuan variabell yang bebas dimana dalam penelitian ini tidak dilakukan penelitian yaitu $1,8 \%$.
\end{abstract}

"Kata Kunci": Pelatihan, Komunikasi, "Kinerja Karyawan"

\section{ABSTRACT}

The purpose of the reseacrh was expected to find the effect of workshop, communication, to employee's performance at the clinic Yamet, either simultaneously or partially. The method used in the preparation of research was quantitative descriptive. The analytical method usedwas multiple linear regression analysis with a population of 50 and a sample of 50 employees, the research used non proability sampling method as sampling method. The result of hypothesis test for workshop variable and communication, partially had value of thitung by value 6.528, and 9.590 each which means that all value of $t_{\text {hitung }} t_{\text {table. }}$. For the result of hypothesis test simultaneously was obtained $F_{\text {hitung }}>F_{\text {table }}$ by value $13.08>3.20$. With level of significance $\alpha=0.05$. It could be concluded that workshop variable and communication partially either simultaneously did has significant influence to employee's performance. With linear regression formula $\hat{Y}=-0.026+0.001 X_{1}+$ $0.048 X_{2}$ It means workshop and communication had influence power to employee's performance. Coefficient of determination by value 0.982 or $98.2 \%$. It means that the workshop, communication had influence power to employee's performance by value $98.2 \%$ and for the remaining by value $1.8 \%$ is another influence from other freevariables which's not included to this reseach.

Keywords: Workshop, Communication, Employee Performance 


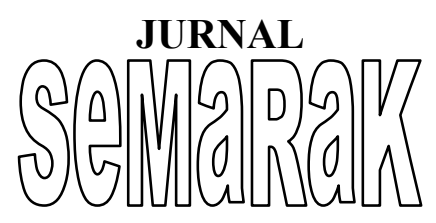

Semarak,Vol. 1, No.3,Oktober 2018, Hal (1-20)

@Prodi Manajemen Fakultas Ekonomi Universitas Pamulang

\section{PENDAHULUAN.}

\section{A. Latar Belakang}

Hal sentral di suatu badan yaitu hal kepegawaian. Kualitas sumber daya manusia mencakup aspek lahiriah dan batiniah, yang menentukan kinerja instansi. Semakin tingginya kualitas karyawan diharapkan semakin tinggi kinerja instansi. Konsep Menurut SP.Hasibuan (2008:50) " sumber daya manusia adalah pokok dan tumpuan bagi perusahaan agar selalu eksis di persaingan yang ada."

Merunut fakta yang ada untuk meningkatkanprofesionalisme sangat diperlukan berbagai kebijakan ,melalui program pelatihan dan faktor lainnya yaitu komunikasi yang akan mempengaruhi kinerja karyawan. Konsep Mangkuprawira (2004:136) manfaat yang diperoleh dari pelatihan selain mengembangkan perusahaan,dapat membantu dalam loylaitas, meningkatkan motivasi dan prestasi, memperbaiki hubungan lintas personal.

Konsep Menurut Siagian (2003) "Salah satu aspek penting di pelaksanaan badan organisasi yaitu komunikasi."

\section{B. Perumusan Masalah}

1. Besaran pengaruhnya antara pelatihan dengan kinerjanya karyawan?

2. Besaran pengaruhnya antara komunikasi dengan kinerjanya karyawan?

3. Besaran pengaruhnya antara pelatihan serta komunikasi dengan cara (bersama-sama) dengan kinerjnya karyawan?

\section{Pembatasan Masalah}

1. Disini dilakukan pemfokusan diantaranya yaitu yang akan dibahas: pelatihan, komunikasi, kinerja karyawan Klinik Tumbuh Kembang Yamet.

\section{D.Tujuan Penelitian.}

Harapannya dapat menjawab halhal terkait yaitu:

1. Diketahui pengaruhnya antara pelatihan dengan "kinerjanya karyawan."

2. Diketahui pengaruhnya antara komunikasi dengan "kinerjanya karyawan."

3. Diketahui pengaruhnya antara pelatihan serta komunikasi secara bersama dengan " kinerjanya karyawan"

\section{TINJAUAN PUSTAKA}

\section{A. Manejemen}

Konsep Menurut Kartonegoro, (2011:3) MIsi dari suatu pengelolaan menajemen harus menjadi prioritas yang dilakukan sebelum berjalannya kegiatan, yang akan menjadi sasaran utama dalam pencapaian kegiatan. Pengelolaan tersebut sebagai suatu proses kesatuan aktivitas kegiatan dengan harapan bisa terselesaikan dengan lebih baik, konsep "Merunut Stephen P. Robbins dan Mary Coulter dalam Assauri, Sofjan (2011:8)."

Merunut SP. Hasibuan (208:50) konsep "Pelaksanaan di dalam Menajemen merupakan terstrukturnya pengetahuan dengan berurutan terdiri dari kreatifitas seni keterampilan dalam mengelola dan mengkaryakan berbagai sumber daya manusia serta sumber daya lainnya dengan maksud tercapainya goal dari kegiatan."

\section{B. Menajemen SDM}

Menajemen SDM menjadi sebidang ilmu yang hadir dan 


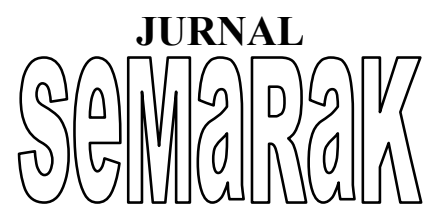

berkembang guna membantu memberikan pemahaman, penekanan, serta gambaran secara menyeluruh pada pengambilan ahir keputusan yang strategis dalam jangka pendek maupun jangka panjang. Terjadi penggabungan antara keilmuan psikologi dengan keilmuan menajemen, yaitu sebagai masukan dari proses penyusunan stuktur, anggaran, kebijakan, prosedur, program. Berperan sebagai subyeknya yaitu manusia. Konsep Malayu Hasibuan S.P (2008)

\section{B. Pelatihan}

Konsep "Ray Sofyandi (2008:113)" pelatihan sebagai berikut; sebagai cara dalam mengembangkan keterampilan, wawasan pengetahuan pegawai melakukan peran, tugas serta kewajibannya. Organisasi dan manajer menggunakan pelatihan untuk meaksanakan tindakan perbaikan serta pencapaian sasaran.

\section{C.Komunikasi}

Konsep Stephen P Robbins (2007;311) komunikasi memiiki kontribusi besar untuk suksesnya suatu kegiatan dengan menyampaikan informasi pelaksanaan kegiatan. Adanya pemahaman yang satu dalam berinteraksi adalah salah satu fungsi komunikasi.

Keberhasilannya komunikasi bisa dipengaruhi oleh suasana dalam pekerjaan serta bagaimana cara -cara penyampaiannya.

\section{Kinerja Karyawan}

Anwar Prabu Mangku Negara (2010:67) konsep mengemukakan : Hasil dari pekerjaan karyawan dapat berupa hasil negative serta hasil kerja positif ,ini berguna untuk memenuhi tujuan ahir dari usaha.

\section{E. Kerangka Pemikiran}

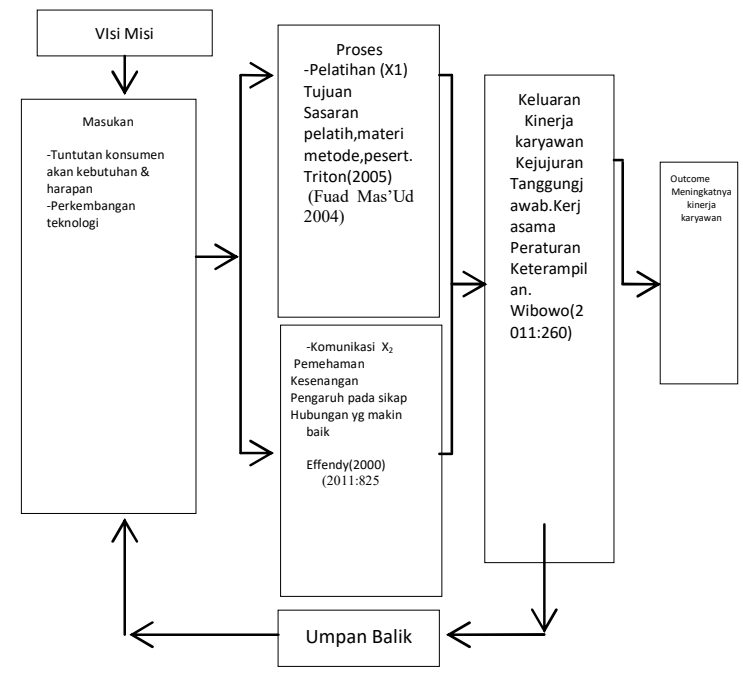

\section{F.Hipotesis Penelitian}

Kebenaran-kebenaran jawaban sementara ini harus diakukan pengujian kembali. Konsep (Riduwan, 2014:35) Mengacu pada model penelitian diatas, :

1. variabel pelatihan memiiki pengaruh baik yang sangat berarti "kepada kinerjanya karyawan."

2. variabel berkomunikasi memiiki pengaruh baik yang sangat berarti "kepada kinerja karyawan."

3.pelatihan dan komunikasi memiiki pengaruh baik yang sangat berarti dengan cara simutan "kepada kinerja karyawan."

\section{METODE PENELITIAN}

\section{A. Waktu serta Tempat \\ Diilakukan di Klinik Tumbuh Kembang Yamet, berlangsung selama 6 bulan, sejak Juni 2018 selesai Desember 2018.}

\section{B. Metode Penelitian}

Disini mengambil "sampel" secara langsung dari "populasi“.Ini adalah ( 
deskriptip kuantitatif). Dengan harapan dapat diketahui pengaruhnya Pelatihan , Komunikasi dengan Kinerja karyawan. "Konsep Sugiyono (2007:13) penelitian kuantitatif." adalah penelitian yang $\mathrm{m}$ emiliki goal ahir melakukan uji kemballi hipotesis. Data dikumpulkan dengan alat instrumen, penganalisaan data sifatnya angka (kuantitatif) dipakai dalam meneliti responden beserta "sampel"

\section{C.Populasi , Sampel}

\section{Populasi}

Merupakan domain bagian suatu objek serta subjek menjadi suatu jumlah serta suatu karakteristik yang sudah dilakukan penetapan. Konsep "Sugiyono (2011:57)." Wiayah Populasi dalam penelitian ini adalah Karyawan Klinik Tumbuh Kembang Yamet Tahun 2017 sebanyak 50 orang.

\section{Teknik Dalam Penentuan Data}

Data primer serta data sekunder merupakan sumber dalam Teknik.

D. Metode Analisis Data

Adapun Metodenya yaitu :

1. Uji Validitas.

$\begin{array}{ll}\text { Peneliti memakai } & \text { "korelasi } \\ \text { Product moment" } & \text {.Uji ini } \\ \text { dipakai dalam } & \text { melakukan } \\ \text { pengukuran } & \text { kesahan } \\ \text { koesionerr. } & \end{array}$

2. Uji Reabilitas

Uji yang berkaitan dengan derajat konsistensi dan stabilitas data atau temuan, Sugiyono(2011:268)

\section{Uji Asumsi Klasik}
a. Uji normalitas
Dalam
mencaritahu, variabel

variabel independent mempunyai distribusi data normal atau mendekati.

b. Uji Multikolinieritas

Untuk menguji ada korelasi antara variabel dependent dan variabel independent, VIF $<10$

c. Uji Heterokedastisitas Dipakai dalam mencaritahu ketidaksamaan varians tiap variabel, Sugiyono (2013:124)

\section{RancanganPengujian} Hipotesis

a. Uji t (Parsial)

Dipakai dalam mencaritahu variabel apakah yang mempengaruhi pelatihan, dan komunikasi kepada kinerja karyawan dengan cara (partial)

\section{b.Koefisien Determinasi}

untuk mengetahui \% nilai kinerja karyawan sebagai variabel terikat

b. Analisis Regresi

1) AnalisisRegresi

Sederhana"

Dipakai dalam mencaritahu berubahnya niai saat dinaik/turunkan variabel, Sugiyono

2)Analisis Regresi Berganda"

Dipakai dalam mencaritahu ada kah pengaruh di kedua variabel, Gozali (2006)

d.Uji F (Simultan)

Dipakai dalam pengujian Untuk menguji pelatihan,komunikasi,terhad ap kinerja karyawan secara bersama-sama 
JURNAL

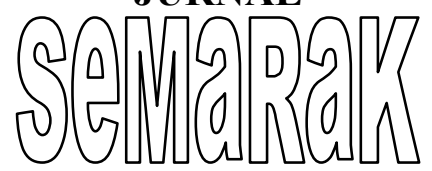

Semarak,Vol. 1, No.3,Oktober 2018, Hal (1-20)

@Prodi Manajemen Fakultas Ekonomi Universitas Pamulang

\section{HASIL DAN PEMBAHASAN}

\section{A.Hasil Uji Instrumen Penelitian} 1. Hasil Uji Validitas

\begin{tabular}{|c|c|c|c|}
\hline No & $\begin{array}{l}\text { "Nilai r } \\
\text { Hitung" }\end{array}$ & $\begin{array}{l}\text { "Nilai r } \\
\text { Tabel" }\end{array}$ & Sipulan \\
\hline \multicolumn{4}{|c|}{ pelatihan $\left(\mathrm{X}_{1}\right)$} \\
\hline 1 & 0,602 & 0,280 & "Valid" \\
\hline 2 & 0,658 & 0,280 & "Valid" \\
\hline 3 & 0,814 & 0,280 & "Valid" \\
\hline 4 & 0,637 & 0,280 & "Valid" \\
\hline 5 & 0,722 & 0,280 & "Valid" \\
\hline 6 & 0,392 & 0,280 & "Valid" \\
\hline 7 & 0,565 & 0,280 & "Valid" \\
\hline 8 & 0,639 & 0,280 & "Valid" \\
\hline \multicolumn{4}{|c|}{ Komunikasi $\left(\mathrm{X}_{2}\right)$} \\
\hline 9 & 0,601 & 0,280 & "Valid" \\
\hline 10 & 0,613 & 0,280 & "Valid" \\
\hline 11 & 0,602 & 0,280 & "Valid" \\
\hline 12 & 0,658 & 0,280 & "Valid" \\
\hline 13 & 0,814 & 0,280 & "Valid" \\
\hline 14 & 0,637 & 0,280 & "Valid" \\
\hline 15 & 0,722 & 0,280 & "Valid" \\
\hline 16 & 0,392 & 0,280 & "Valid" \\
\hline \multicolumn{4}{|c|}{ Kinerja karyawan $(\mathrm{Y})$} \\
\hline 17 & 0,665 & 0,280 & "Valid" \\
\hline 18 & 0,424 & 0,280 & "Valid" \\
\hline 19 & 0,731 & 0,280 & "Valid" \\
\hline 20 & 0,678 & 0,280 & "Valid" \\
\hline 21 & 0,775 & 0,280 & "Valid" \\
\hline 22 & 0,687 & 0,280 & "Valid" \\
\hline 23 & 0,681 & 0,280 & "Valid" \\
\hline 24 & 0,455 & 0,280 & "Valid" \\
\hline
\end{tabular}

Sugiyono (2009:172) "Dipakai dalam mencaritahu valid tidaknya tiap variabel ,mengacu pada. " $\mathrm{r}_{\text {tabel }}$ product moment, $d f=(\dot{\alpha}, \mathrm{n}-2) . " \quad$ responden sejumlah 50 pegawai akan dihasilkan " $\mathrm{r}_{\text {tabel }}=0,280 \quad$ signifikansi $<0,05$. Disimpulkan valid dengan mengacu “" $r_{\text {hitung }}>r_{\text {tabel }}$."

a. "Uji Reliabilitas"

Dalam Gozali(2006: 182) "Akan disimpulkan "reliabel," dengan alasan mempunyai nilai "Cronbach Alpha nya yang melebihi 0,6." Setelah diakukan penghitungan didapatkan hasil niai Conbrachnya melebihi 06 yaitu 0,971.Dan didapatkan " $\mathrm{r}$ tabel 0,280 " dan 5\% signifikan". Kesimpulannya Conbrach alpha $>0,60(0,971)$ artinya item-item tersebut bersifat reliable. semuanya reliabel dengan interpretasi kuat sehingga bisa dijadikan alat pengukur (variabel tersebut ).

\section{Hasil Uji Asumsi Klasik \\ a. Hasil Uji Normalitas}

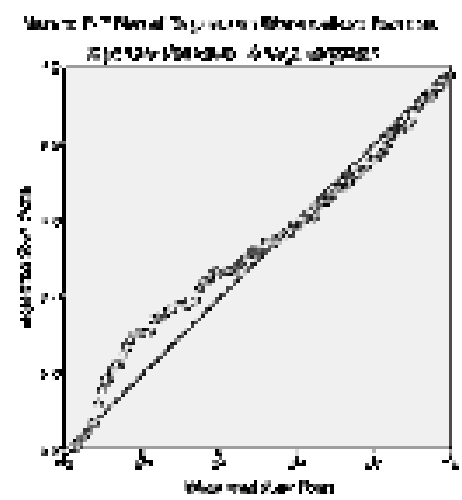

"Dapat dilihat dari grafik di atas bahwa penyebaran titik mendekati dan titik terbentuk disekitar "garis lurus diagonal, "dapat diartikan bahwa regresi tersebut menghasilkan niai-niai reesidu yang normal. Selanjutnya dalam mencaritahu kenormalan distribusi data( Nilai signifikan melebihi 0,05) yang terkait tersebut harus dilakukan dengan pengujian 'One Sample' Kolomogorov Smirnov dipakai untuk mencaritahu residu tersebut distribusinya dalam keadaan normal ataukah sebaliknya (tidak normal).

"One-Sample Kolmogorov-Smirnov Test"

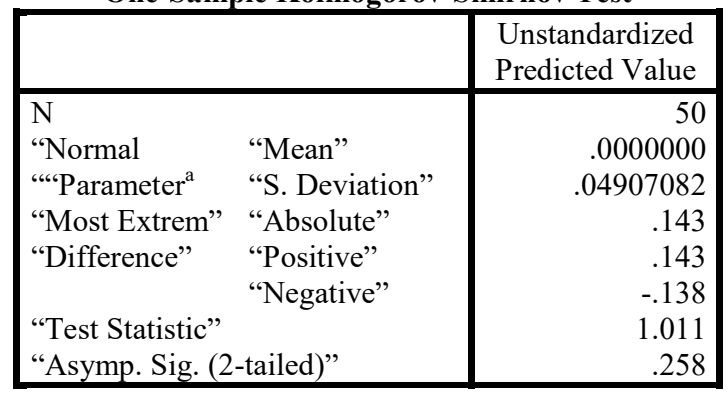

a. "Test distribution is Normal."

b. "Calculated from data."

c. "Lilliefors Significance Correction."

"Jika diihat hasil output test komogrov tersebut dapat dikatatakan niai residu dalam keadaan normal yaitu "nilai signifikansi 0258 (Asymp. Sig 2tailed) ". Dikarenakan signifikan melebihi nilai $0,05(0,258>0,05)$." 


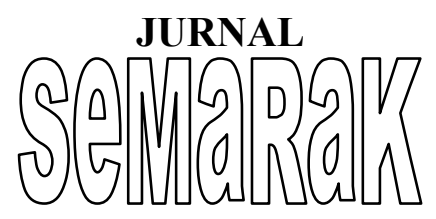

Semarak,Vol. 1, No.3,Oktober 2018, Hal (1-20)

@Prodi Manajemen Fakultas Ekonomi Universitas Pamulang

a. Dependen Variable: Kinerja pegawai

\section{b. "Hasil Uji Multikolinieritas"}

\begin{tabular}{|c|c|c|c|}
\hline \multirow{2}{*}{\multicolumn{2}{|c|}{ "Model" }} & \multicolumn{2}{|c|}{ Collinearity Statistics } \\
\hline & & Tolerance & VIF \\
\hline & (Constant)" & & \\
\hline & "Pelatihan" & .643 & 1.556 \\
\hline & "Komunikasi" & .643 & 1.556 \\
\hline
\end{tabular}

Dari hasil output data didapatkan bahwa gejala -gejala terjadinya korelasi tidak ada dengan mengacu pada "VIF nilainya kurang dari sepuluh $(<10)$ serta didapatkan nilai toleransi melebihi 0,10 ( $>0,10$ ). Kesimpuannya tidak adanya korelasi pada masing-masing variabel bebasnya".

\section{c. "Hasil Uji Heteroskedastisitas"}

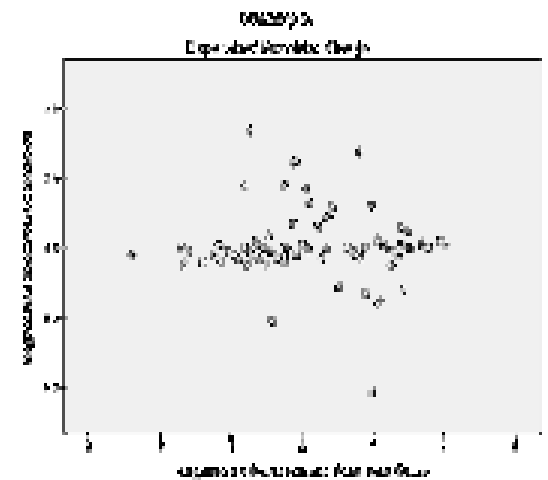

Disimpulkan

permasalahan heteroskedastisitas tidak ada didalam regresi ini. " titik-titik membentuk pola yang tidak jelas, serta titik-titik tersebut melakukan penyebaran pada bagian atas dan bagian bawah angka 0 sumbu $\mathrm{Y}$, hal tersebut yang terlihat pada hasil keluaran gambaran .

\section{B. "Analisis Verifikatif}

Hasil Pengaruh Secara Partial"

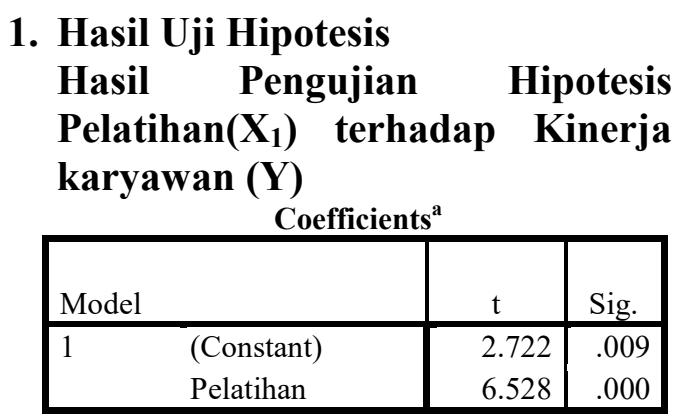

Berdasarkan output diperoleh hasil sebagai berikut: Hasil uji parsial menunjukkan variabell pelatihan memiiki "pengaruh" yang baik kepada variabel" kinerja" dilihat dari nilai $\mathrm{t}$ hitung untuk variabel pelatihan $(6.528)>$ nilai $t$ tabel $(1,677)$ dan dihasilkan variabel pelatihan memiliki pengaruh sangat berarti kepada variabel kinerja, signifikansi $\mathrm{t}$ untuk variabel pelatihan signifikan $(0,000)$ kurang dari batas " signifikan" yaitu $(0,05)$, oeh sebab itu Hipotesis 0 ditolak dan Hipotesis a tidak ditolak untuk variabell pelatihan. Dengan demikian, ada pengaruh baik yang sangat berarti antara variabel pelatihan kepada "kinerjanya karyawan."

\section{"Hasil Koefisien Determinasi (R-} Square) / $\mathrm{X}_{1}$ terhadap Y."

\begin{tabular}{|l|r|r|r|}
\hline \multicolumn{1}{|c|}{ "Model Summary" } \\
\hline "Model" & "R" & "R Square" & $\begin{array}{l}\text { "Adjusted } \\
\text { R Square" }\end{array}$ \\
\hline 1 & $.9911^{\text {al }}$ & .982 & .982 \\
\hline
\end{tabular}

Berdasarkan output tersebut didapatkan hasil "R square" 0,982 dan diubah menjadi persen yaitu 98,2 \%. "variabell bebas" lainnya yang meberikan pengaruh tetapi tidak dilakukan penelitian yaitu $1.8 \%$. Hal ini menunjukkan variabel pelatihan pengaruhnya terhadap kinerja karyawan adalah sebesar $98,2 \%$

\section{"Hasil Analisis Regresi / $\mathbf{X}_{1}$ terhadap} Y"

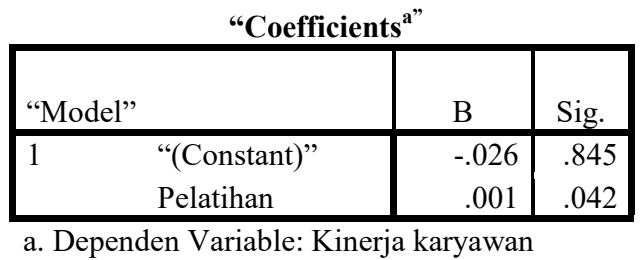


Berdasarkan output pada tabel 4.26, diperoleh hasil "persamaan regresi":" $\hat{Y}=$ $-0.026+0.001 \mathrm{X}_{1}$ "

Penjelasannya adalah : Konstanta sebesar-.026 menyatakan bahwa tanpa variabel pelatihan, kinerja mempunyai nilai yaitu sebesar 0.026 . Nilai coefficents sebanyak "0.001" yang berarti andaikan pelatihan meningkat sebesar "satu satuan" akan berdampak peningkatan sebanyak 0,001 pada kinerja.

Pelatihan memiliki kemampuan untuk mempengaruhi hasil kinerja pada "karyawan". Kesimpulan nya adalah pelatihan mempunyai pengaruh kepada hasil kinerja karyawan.

"Hasil Pengujian Hipotesis komunikasi $\left(\mathrm{X}_{2}\right)$ terhadap Kinerja karyawan $(\mathrm{Y})$ )"

\begin{tabular}{|ll|c|c|}
\hline \multicolumn{2}{|c|}{ "Coefficients" } \\
\cline { 3 - 4 } Model & $\mathrm{t}$ & Sig. \\
\cline { 3 - 4 } & & & \\
\hline 1 & (Constant) & 2.722 & .009 \\
& Komunikasi & 9.590 & .000 \\
\hline
\end{tabular}

a. Dependen Variable: Kinerja

Berdasarkan output tabel diperoleh hasil sebagai berikut: Hasil uji parsial menunjukkan komunikasi memiliki pengaruh baik "(positif)" kepada variabel" kinerja". dilihat dari hasil tersebut $(9,590)$ yaitu nilai t hitung untuk "variabel komunikasi" yang melebihi besaran "t tabel" $(1,677)$ dan didapatkan hasil "variabel " komunikasi mempengaruhi "variabel" kinerja. " signifikansi t " untuk variabel komunikasi yaitu signifikan " 0,000 " batasnya kurang besar dari " 0,05 " oeh sebab itu Hipotesis 0 ditolak serta Hipotesis a tidak ditolak untuk variabel komunikasi. Maka dengan itu secara parsial "variabel" komunikasi memiliki pengaruh yang sangat berarti dengan kinerja karyawan.

"Hasil Koefisien Determinasi (RSquare) / $\mathrm{X}_{2}$ terhadap Y."

"Model Summary"

\begin{tabular}{|l|r|r|r|}
\hline "Model" & "R" & "R Square" & $\begin{array}{l}\text { "Adjusted } \\
\text { R Square" }\end{array}$ \\
\hline "1" & .984 & .969 & .725 \\
\hline
\end{tabular}

a. Predictors: (Constant), komunikasi

Berdasarkan output tabel dapat dilihat bahwa nilai $\mathrm{R}$ square 0,969 dan diubah menjadi persen yaitu 96,9\%. Adapun 96,6\% adalah besarannya variabel komunikasi dalam me mpengaruhi "variabe"l kinerja. Variabel bebas lainnya yang memberikan pengaruh tetapi tidak diakukan penelitian yaitu $3,1 \%$

"Hasil Analisis Regresi / $\mathrm{X}_{2}$ terhadap Y"

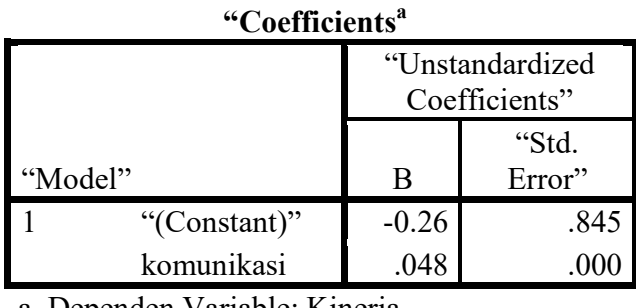

Berdasarkan output pada tabel diperoleh hasil "persamaan regresi" " $\hat{Y}=$ $-0.026+0.048 \mathrm{X}_{2}$ " Penjelasannya adalah : Konstanta sebesar -0.026 menyatakan bahwa tanpa variabel komunikasi, kinerja mempunyai nilai yaitu sebesar -026 . Nilai coefficents yaitu 0.048 . yang berarti andaikan komunikasi meningkat sebesar "1 satuan" akan berdampak peningkatan sebanyak 0,048. Pada persamaan tersebut dapat dilihat bahwa komunikasi memiliki kemampuan mempengaruhi kinerja. Kesimpulannya adalah komunikasi berpengaruh kepada "kinerja."

4. Hasil Pengujian Pengaruh Pelatihan,Komunikasi terhadap kinerja karyawan

\begin{tabular}{|c|c|c|}
\hline Model & "F" & "Sig". \\
\hline 1 "Regression" & 130.803 & $.000^{\mathrm{b}}$ \\
\hline
\end{tabular}




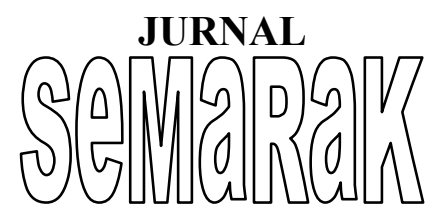

"Residual"
"Total"

a. Dependen "Variable": Kinerja

"b. Predictors: (Constant "pelatihan,komunikasi

Berdasarkan output tabel

"nilai"(130.803) yaitu F hitung melebihi besaran dari nilai " $F_{\text {tabel" }}(3,20)$ adapun "signifikan". $\alpha(0,000)$ yang tidak melebihi "alpha 5\% (0,05)." Kesimpulannya didapatkan bahwa Hipotesis 0 tidak diterima serta Hipotesis a tidak ditolak.. maka dengan cara simultan pelatihan, komunikasi memiliki pengaruh yang sangat berarti kepada "kinerja."

"Hasil Koefisien Determinasi (RSquare) / $\mathbf{X}_{1}, \mathbf{X}_{2}, \mathbf{X}_{3}$ "terhadap $\mathrm{Y}$

\begin{tabular}{|l|r|r|r|}
\hline "Model" & "R" & "R Square" & $\begin{array}{r}\text { "Adjusted } \\
\text { R Square" }\end{array}$ \\
\hline 1 & .991 a & .982 & .982 \\
\hline
\end{tabular}

"a. Predictors: (Constant pelatihan,komunikasi"

"b. Dependen Variable: Kinerja “

Hasil output yaitu R Square 0,982 dan diubah menjadi persen yaitu 98,2 \% . Artinya bahwa persentase pengaruhpelatihan,dan komunikasi terhadap kinerjanya besarannya $98,2 \%$, variabell bebas lainnya besarnnya yaitu $1,8 \%$ tetapi tidak dilakukan penelitian .

\section{"Hasil Analisis Regresi / $\mathbf{X}_{1}, \mathbf{X}_{2}$,} terhadap Y"

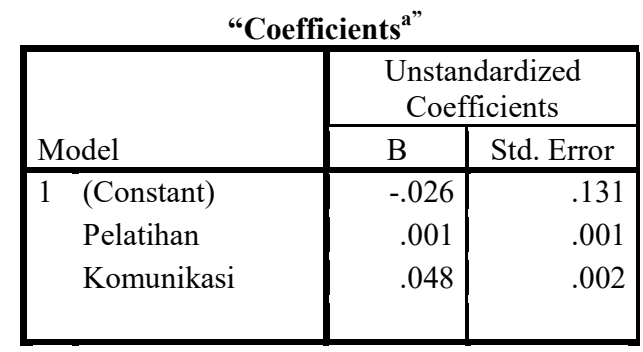

a. Dependen Variable: Kinerja

Berdasarkan output hasil "persamaan regresi ": $\hat{Y}=-0.026+0,001 \mathrm{X}_{1}+0,048$ $\mathrm{X}_{2}$." artinya pelatihan serta komunikasi memiliki pengaruh kepada "kinerja". Angkakonstanta 0.026 menyatakan bahwa tanpa variabel pelatihan dan komunikasi Y nilai besarannya 0.026 . nilai coefisien
0,048 yang berarti andaikan pelatihan meningkat sebesar "satu-satuan" dan variabel pelatihan tetap, akan berdampak peningkatan pada kinerja sebanyak 0,048 .Dengan bertambahnya 1 satuan pada variabel komunikaasi serta variabel "pelatihan" tetap akan berdampak 0,048 pada peningkatan kinerja. Kesimpulannya pelatihan serta kommunikasi meimiliki pengaruh kepada "kinerja".

\section{Pembahasan}

Merujuk pada hasil yang diperoleh dari deskripsi penganalisaan dilakukanlah pembahasan berdasar frekuensi pemilihan opsi pada setiap pernyataan pada variabel independen dan dependen (variabel pelatihan ,komunikasi dan Kinerja) yang diajukan kepada responden penelitian sebagai berikut:

\section{Variabel pelatihan $\left(X_{1}\right)$}

Hasil Hipotesis disimpulkan pelatihan mempunyai"pengaruh" yang sangat berarti kepada "kinerja". Pembahasan pada "penelitian" ini memperkuat pendapat beberapa peneliti yang lain. Beberapa diantaranya yaitu Syahrizal (2016), yang bisa disimpulkan bahwa pelatihan memiliki pengaruh baik yang sangat berarti kepada "kinerjanya" pegawai.

\section{Variabel "Motivasi" $\left(X_{2}\right)$}

Kesimpulan yang bisa didapa dari Hipotesis yaitu komunikasi memiliki "pengaruh" sangat berarti kepada "Kinerjanya karyawan". Pembahasan pada "penelitian" ini bisa memperkuat pendapat beberapa peneliti yang lainnya. Beberapa diantaranya yaitu Rizki dani (2009), dimana bisa disimpulkan yaitu motivasi memiliki pengaruh baik yang sangat berarti kepada "kinerjanya" pegawai.

\section{Variabel "Pelatihan" $\left(\mathrm{X}_{1}\right) \mathrm{dan}$ komunikasi (x2)}




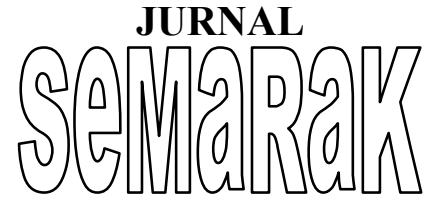

P-ISSN 2615-6849 E-ISSN 2622-3686

Semarak,Vol. 1, No.3,Oktober 2018, Hal (1-20)

@Prodi Manajemen Fakultas Ekonomi Universitas Pamulang
Hasil Hipotesis diperoleh kesimpulan bahwa pelatihan dan komunikasi memiliki "pengaruh" yang sangat berarti kepada "Kinerjanya karyawan". Di pembahasan ini yang bisa disimpulkan yaitu pelatihan,dan komunikasi bersamasama memiliki pengaruh baik yang sangat berarti kepada "kinerja" pegawai.

\section{KESIMPULAN DAN SARAN}

\section{A. Kesimpulan}

Pelatihan mempunyai "pengaruh "yang sangat berarti kepada "kinerja". Besaran berpengaruhnya dari pealtihan yaitu 98.2\%.Serta besaran yang mempengaruhi di varriabel bebas yang lainnya yang tidak dilakukan penelitian yaitu $1.8 \%$. Persamaan regresi linier $\hat{Y}=$ $0.026+0.001 \mathrm{X}_{1}$.

Komunikasi mempunyai "pengaruh "yang sangat berarti kepada "kinerja". Besaran berpengaruhnya dari pealtihan yaitu 96,9\%. Serta besaran yang mempengaruhi varriabel bebas yang lainnya yang tidak dilakukan penelitian yaitu $3.1 \%$. Persamaan regresi linier $\hat{Y}=$ $0.026+0.048 \mathrm{X}_{2}$.

Pelatihan dan komunikasi secara bersama -sama memiliki "pengaruh "yang sangat berarti kepada "kinerja". Besaran pengaruhnya dari pelatihan serta komunikasi yaitu $982 \%$. Serta besaran yang mempengaruhi berasal dari varriabel bebas yang lainnya yang tidak dilakukan penelitian yaitu $1.8 \%$. Persamaan regesi linier $\hat{\mathrm{Y}}=-0.026+0,001 \mathrm{X}_{1}+0,048 \mathrm{X}_{2}$.

\section{B. Saran}

Bagi klinik Yamet merujuk pada jawaban yang diperoleh di kuesioner daam ketiga variabel didapatkan temuan sebagai berikut:

1. Pelatihan 9responden (18\%) menyatakan ragu- ragu pada sub indikator ketersediaan fasilitas penunjang program pelatihan, disarankan kepada pimpinan Klinik Yamet agar pengembangan dan pelatihan karyawan harus dilaksanakan berkelanjutan guna meningkatkan kompetensi dan komitmen sehingga tercapai strategi bisnis.

2. Komunikasi

9 responden (18\%) menyatakan ragu-ragu pada sub indikator efisiensi komunikasi,

Disarankan pimpinan klinik Yamet untuk lebih meningkatkan keakraban antar karyawan secara bekesinambungan ,sehingga interaksi, koordinasi di lingkungan kerja dapat terjalin dengan baik

3. Kinerja

9 responden (18\%) menyatakan ragu - ragu pada sub indikator prakarsa, di sarankan untuk memotivasi karyawan dalam berinovasi dalam karya dengan memberikan penghargaan pada yang berprestasi.

\section{DAFTAR PUSTAKA}

Ambar Teguh Sulistiyani dan Rosidah. 2008. Manajemen Sumber Daya Manusia Graha Ilmu,Yogyakarta.

Anwar Prabu Mangkunegara,2006, Manajemen SDM Dalam Organisasi Publik dan Bisnis, Rosdakarya,Bandung , 2011, Manajemen Sumber Daya Manusia perusahaan, Remaja Rosdakrya,Bandung.

Arikunto, Suharsismi., 2011, Prosedur Suatu Penelitian; Pendekatan Praktek, Edisi Revisi V, Rineka Cipta, Jakarta.

Efendy,2000, Ilmu Teoridan Filsafat 
JURNAL

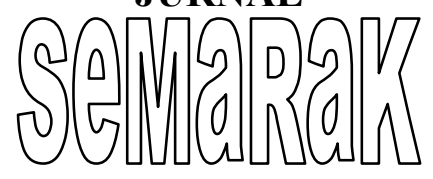

P-ISSN 2615-6849 E-ISSN 2622-3686

Semarak,Vol. 1, No.3,Oktober 2018, Hal (1-20)

@ Prodi Manajemen Fakultas Ekonomi Universitas Pamulang

Komunikasi, PT Rosda Karya, Tarigan, Robins, "Ekonomi Regional Teori Bandung

Ghozali, Imam,2011, Aplikasi Analisis dan Aplikasi", Penerbit PT Bumi

Multivariate dengan program Aksara, Jakarta, 2015.

SPSS, Universitas Diponegoro, Semarang.

Gison, James, 2006, Perilaku Organisasi,

Graha Ilmu Spector,

Yogyakarta.

Gorda, 2006, Manajemen Sumber Daya

Manusia, Widya Kriya

Gematama, Denpasar.

Kertonegoro, 2011,Prinsip dan Teknik Manajemen, Bandung

Mangkuprawira, 2004, Manajemen Sumber Daya Manusia, Galia Indonesia, Jakarta

Ray dalam Sofyandi, 2008, Manajemen Sumber Daya Manusia, Graha Ilmu. Yogyakarta

Stephen Robbins, 2007, Perilaku organisasi, PT Indeks kelompok gramedia, Jakarta

Sugiyono, 2007, Sattistika Untuk Penelitian,CV Alfabetha, Bandung

----------, 2011,Metode Penelitian Kuantitatif,Kualitatif danR\&D, Alfabetha, Bandung

SP Hasibuan, 2008, Manajemen Dasar, Graha Ilmu, Yogyakaarta

Stephen P Robbin dan Mary Coulter dalam Assauri, 2011,

Sukirno, Sadono, "Makro Ekonomi Teori Pengantar Edisi Ketiga", PT Raja Grafindo Persada, Jakarta, 2004.

Sirojuzilam, "Disparitas Ekonomi dan Perencanaan Regional, Ketimpangan Ekonmi Wilayah Barat dan Wilayah Timur Provinsi Sumatera Utara", Pustaka Bangsa Press, Jakarta, 2008. 